\title{
Travel Mode and Travel Route Choice Behavior Based on Random Regret Minimization: A Systematic Review
}

\author{
Peng Jing *, Mengxuan Zhao, Meiling He and Long Chen \\ School of Automobile and Traffic Engineering, Jiangsu University, Zhenjiang 212013, China; \\ zhaomengxuango@163.com (M.Z.); hemeiling@ujs.edu.cn (M.H.); chenlong@ujs.edu.cn (L.C.) \\ * Correspondence: jingpeng@ujs.edu.cn
}

Received: 21 March 2018; Accepted: 11 April 2018; Published: 14 April 2018

\begin{abstract}
In recent years, traffic congestion has become increasingly serious and the urban environment has deteriorated, posing a challenge to the modern sustainable transportation system. Sustainable travel behavior is a solution that many scholars recognize as being an important aspect in the development of socially, environmentally, and economically sustainable communities. Increasing numbers of studies analyzed the travel choice behavior based on Random Regret-Minimization (RRM) model. RRM considers multiple attribute compromises to capture the traveler's choice behavior based on minimizing the perceived regret decision criteria. Travel route choice and travel mode choice are interrelated and mutual restraint when a traveler makes a travel decision. To our knowledge, there are limited literatures that overall considered travel mode and travel route choice behavior based on RRM at present. This paper aims to fill this gap and presents a literature review for the application of RRM on sustainable travel mode and travel route choice behavior from empirical issues, influencing factors, theories and methods to evaluate RRM's potential and limitations as a discrete model of travel choice behavior. The results will provide reference for researchers to study this field and develop novel strategies to promote the sustainable traffic system in the future.
\end{abstract}

Keywords: Random Regret Minimization; regret theory; choice behavior; travel mode choice; travel route choice

\section{Introduction}

With the arrival of the information age, the expansion of the population and the deteriorating environment, the modern sustainable transportation system is facing severe challenges. The phenomenon of traffic congestion is becoming increasingly serious, which is inevitable because traffic demand exceeds the traffic supply and has become a critical problem to be solved urgently in the major cities of the world. In order to achieve the balance between supply and demand and promote the sustainable development of the traffic system, traffic engineering scholars put forward the concept of Traffic Demand Management (TDM) in 1980s, whose core is inducing people's travel behavior to alleviate traffic congestion [1]. Travel mode and travel route are the essential parts of travel choice.

The suitable travel choice should feature the highest efficiency, the best program, and the greatest satisfaction from a traveler. Since the mid-seventies, the majority of the travel demand model has used the Random Utility Maximization (RUM) model rooted in discrete choice analysis [2,3]. The RUM model assumes that when a traveler is faced with a number of travel modes and travel routes, he/she will choose the one with the highest utility. Although the RUM model had great achievements to explain travel mode and travel route choice behavior, Chorus [4] presents an alternative approach to the RUM model of travel choice rooted in Regret Theory (RT) [5-7] and was coined Random Regret-Minimization (RRM). 
RT was presented decades ago [6], and, similar to Prospect Theory (PT) [8], it originally assumed a decision-making process under uncertainty. RRM constitutes an alternative to both Utility Theory (UT) and PT. When an individual's awareness perceives the product of the non-chosen alternative to be better than the result of the chosen alternative, it will build an emotion called regret [9]. The RRM model develops from the angle of bounded rationality and the scheme between multiple attribute trade-offs to capture the traveler's choice of psychological and traffic behavior based on minimization of the perceived regret decision criteria [10]. Therefore, we should minimize Expected Regret (ER) when making a choice between alternatives.

The concept of regret as a determinant of decisions is often employed in areas, such as psychology [11,12], marketing [13] and finance [14]. Recently, RRM model has been used to analyze and predict a wide variety of choices, such as departure time choices, route choices, mode-destination choices, activity choices, on-line dating choices, health-related choices and policy choices $[15,16]$.

Recently, regret-based choice models have gained in popularity rapidly in travel behavior research as an alternative approach to modelling choice behavior both under conditions of certainty and uncertainty $[17,18]$. Chorus is the authority figure in the application of regret theory to travel mode and travel route choice behavior. He shows that RRM can be extended towards the case of risky travel choice, using the notion of ER [4]. Recently, he compared RUM with RRM in terms of theories and equations, and showed their respective benefits of the scope of application [19].

Traditionally, the RUM model has dominated the travel choice behavior since it was accepted [10]. Studies to date suggest that the RRM is just as parsimonious as the standard RUM model, and it is unlike other models of contextual effects, which typically require the estimation of additional parameters [10,20]. Compared with the RUM, the RRM has two advantages: (1) The RRM features logit choice probabilities and is easily estimable by using conventional discrete choice software packages in the research field [20-22]; (2) The RRM model does not exhibit the property of independence from irrelevant alternatives (IIA), even with the assumption of independent and identically distributed (IID) error terms [20]. Therefore, RRM plays an important role in travel choice behavior. However, the applications of the regret model to analyze travel choice behavior are too few and fragmented for researchers to understand the regret model fully [10]. Hence, it is essential to present a structured systematic review of the current state of the RRM and summarize the applications in travel choice as a behavioral paradigm.

Travel choice behavior is a combination of travel route choice and travel mode choice. Both are interrelated and mutually restrained at the same time. However, the study of travel behavior based on RRM is usually only focused on the one aspect which is obviously out of line with the actual situation. To our knowledge, there is no literature review overall concerning travel mode and travel route based on RRM at present. This paper reviews current empirical studies about the application of RRM on travel mode and travel route choice behavior, with a view to develop a system framework for evaluation of the underlying RRM nature of travel behavior. Specifically, the paper has four objectives: (1) analyzing the current situation of travel mode choice and travel route choice behavior based on RRM; (2) identifying and sorting out the influencing factors and research methods that have been considered in the analysis of travel mode and travel route choice behavior based on the RRM model; (3) enabling an assessment of RRM's potential and its limitations as a model of discrete travel choice behavior; (4) summarizing a research framework based on RRM, which will provide convenience for researchers to update the information base of a researcher returning to this field in the future. Completing these four research goals to assist the transportation planning and management department in planning and designing transportation systems serves the needs of social-economic development and sustainability.

The body of this paper is structured as follows: Section 2 illustrates the methods of literature search and screening criteria. Section 3 summarizes the results of a systematic review. The quality of reviewed studies about these studies is provided in Section 4. Section 5 presents a systematic 
discussion. The conclusion is proposed in Section 6. Lastly, the author presented some suggestions for future work.

\section{Method}

\subsection{Search Strategy}

According to the PRISMA (preferred reporting items for systematic reviews and meta-analyses) guidelines [23], seven databases were searched, namely ScienceDirect, Web of Science, Academic Search Complete, Pub Med, TRID, Eric, Cambridge Journals Online, for application of regret model to travel mode choice and travel route choice behavior in March 2017. The first three databases are integrated databases. The last four databases involve many subjects for their journals, such as life sciences, engineering, transport, mathematics, economics, psychology, sociology and behavioral sciences.

In light of the research topic of this paper, the search terms were incorporated into three types and then one term from each category must be used in combination: (1) regret theory, regret model, random regret-minimization model; (2) travel mode, transportation mode, traffic mode, travel route, transportation route, traffic route; (3) choice behavior, decision behavior, identify behavior. The search terms were included in the title, abstract, topic and keywords in advanced search, accounting for the different search languages for each database to make corresponding adjustments that must match the specific structure of each database. The references were also included in the scope of the search for some literatures which have more influential factors.

\subsection{Inclusion and Exclusion Criteria}

In order to be eligible for inclusion in the review, studies had to: (1) be published in a peer-reviewed English journal; (2) identify related variables based on RT; (3) get empirical results from the application of regret model; (4) be related to the choice behavior of travel mode or travel route; and (5) have at least one variable related to travel as a dependent variable.

\subsection{Data Extraction}

Using the matrix method to pick up a standardized data extraction table from the reviewed papers, the information was abstracted from each reviewed paper included study characteristics (study site, study design, study area, study duration, author), theoretical framework (e.g., RT, UT, PT), model (e.g., RRM model, RUM model), prediction and estimation method, and software needed to build models and analyze data. In order to illustrate high inter-rater reliability, the author verified it from $80 \%$ of the extracted data.

\subsection{Quality Assessment}

This paper tailored a Methodological Quality Scale (MQS) for the existing research [24-26]. The quality of the included studies in this overview is carefully assessed through evaluation description which has four aspects: (1) assessing data collecting methodological quality; (2) theory utilization; (3) methods utilization; and (4) assessing comprehensiveness of factors.

In order to appraise the methodological quality concretely, the modified checklist comprises three standards: study design, adequate sample size selection, and whether the study object is clear. The study design includes experimental, case control, longitudinal study and cross-sectional study. Longitudinal study is more rational and persuasive [27]. Adequate sample size calculation is of importance to determine the number of participants. Accordingly, adequate sample size selection was chosen in the checklist as one of the measurements. Travel behavior study is one of the most complex studies; selecting adequate sample size and study object will make our investigation more targeted and make our research more specific. Therefore, we define the research object for the study as also a key point. A suitable theoretical framework can lead to more accurate mode share forecasts and has important implications for evaluating urban transport plans and policies [28]. If the study had a 
comparative analysis for the regret theory and other theoretical models that will improve the article quality further. A completed method plays an important role in an academic article. Choosing a suitable mathematical method can be a detailed analysis of the relationship between the variables in the model. Determining the reliability parameters will make the study stricter. Finally, obtaining a convincing analysis of the results is critical. It is an important step to select the relevant influencing factors to study the behavior of travel mode and travel route choice. Manifest variables refer to observable variables. Latent variables denote those that cannot be observed directly or cannot be observed that need to be synthesized by other methods. Customarily, they are psychological variables [29]. Psychological factors are more and more imperative for the study of travel choice behavior.

All papers were evaluated on 9 criteria listed in Table 1. The possible range of evaluation scores was 2 to 13 with a higher number indicating better quality.

Table 1. Checklist for evaluating studies' quality.

\begin{tabular}{|c|c|c|}
\hline Criterion & Description & Score \\
\hline \multicolumn{2}{|c|}{ Assessing data collecting methodological quality } & $2-6$ \\
\hline \multirow{2}{*}{ Study design } & Experimental, case control, or longitudinal study & 2 \\
\hline & Cross-sectional study & 1 \\
\hline \multirow{3}{*}{ Adequate sample size selection } & Large $(>300)$ & 3 \\
\hline & Medium (100-300) & 2 \\
\hline & Small $(<100)$ & 1 \\
\hline \multirow{2}{*}{ Indicating the study object } & Included & 1 \\
\hline & Not included & 0 \\
\hline Assessing theory utilization & & $0-2$ \\
\hline \multirow{2}{*}{ Application of regret theory } & Included & 1 \\
\hline & Not included & 0 \\
\hline \multirow{2}{*}{ Comparative analysis } & Included & 1 \\
\hline & Not included & 0 \\
\hline Assessing methods utilization & & $0-3$ \\
\hline \multirow{2}{*}{ Application of statistical methods } & Included & 1 \\
\hline & Not included & 0 \\
\hline \multirow{2}{*}{ Goodness of fit test } & Included & 1 \\
\hline & Not included & 0 \\
\hline \multirow{2}{*}{ Parameter selection reliability testing } & Tested & 1 \\
\hline & Not tested & 0 \\
\hline \multicolumn{2}{|c|}{ Assessing comprehensiveness of factors } & $0-2$ \\
\hline \multirow{3}{*}{ Analysis of influencing factors } & Included manifest variables and latent variables & 2 \\
\hline & Only included manifest variables or only include latent variables & 1 \\
\hline & Not tested & 0 \\
\hline
\end{tabular}

\section{Results}

The search and retrieval process is shown in Figure 1. The numbers of literatures searched from each database were 30,189 (Cambridge Journals Online), 108 (Web of Science), 1781 (Science Direct), 120 (TRID), 4562 (Eric), 71 (PubMed), and 86 (Academic Search Complete). After removing duplicates, a total of 7231 unique records were found from seven databases and additional manual searching. Then following the screening of titles and abstracts that 244 was identified. It is worth noting that the paper will not be included in the literature to be reviewed if it does not explicitly indicate that the travel choice type is travel mode or travel route choice. For instance, some papers researched departure time choice, destination choice and travel information base on RT [30-33]. If the article studied travel mode and travel route choice behavior, but it is not an empirical article, it was not screened into the retrieved literature. For instance, Tien Mai et al. considered the similarities between RRM and mother logit when he analyzed the route choice modes. However, he did not make an empirical analysis, so it was not reviewed in this paper [34]. The reference lists of reviews excluded were reviewed and 
potential papers were identified. Eventually, 20 published papers that met all criteria were included in the review, as showed in Figure 1.

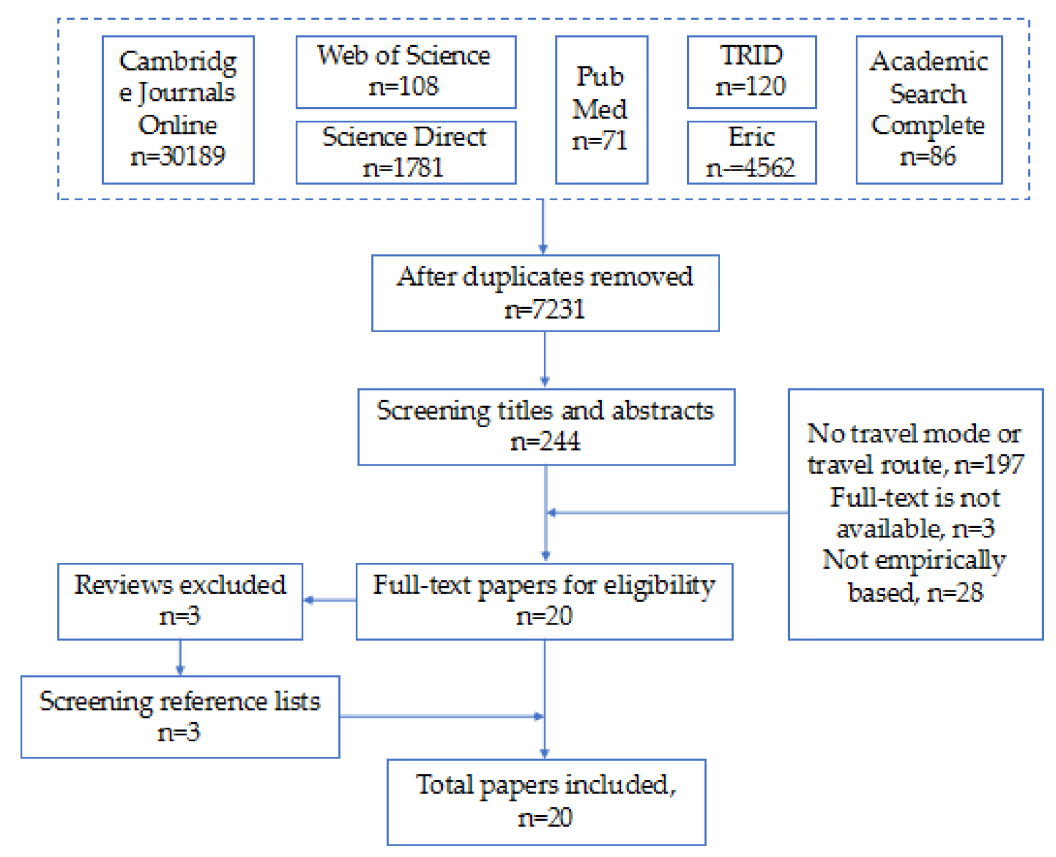

Figure 1. The flowchart of systematic review process.

\subsection{Features of Reviewed Studies}

Basic information about the twenty papers is listed in Table 2. These papers were from fourteen different journals: four papers were from Transportation; two papers were from Transportation Research Part A; two papers were from Transportation Research Part B; two papers were from The Journal of Choice Modelling; ten papers were published in six different journals; and thirteen of these papers belong to the field of transportation. These papers were all published after 2008. Caspar G. Chorus was the first scholar to put forward RRM model which can be applied in travel choice as a behavioral paradigm. All six papers by Caspar G. Chorus, which came from the Netherlands, were studied and he made a great contribution to the research in this field $[4,17,18,35-37]$. Two papers were written by Carlo Giacomo Prato which were from Denmark [36,37]. Other articles were undertaken in the Netherlands $(n=1)$, Australia $(n=1)$, Chicago $(n=1)$, China $(n=1)$, United Kingdom $(n=2)$, and India $(n=1)$. 
Table 2. Summary of studies included in this systematic review. RP: revealed preference; SP: stated preference.

\begin{tabular}{|c|c|c|c|c|c|c|c|c|c|}
\hline Lead Author & Pub. Year & Country & Journal & Discipline & Sample Size & Data RP/SP & Choice Type & Study Object & References \\
\hline Sunghoon Jang & 2017 & Netherlands & $\begin{array}{l}\text { Transportmetrica A: Transport } \\
\text { Science }\end{array}$ & Transport Science & 1158 & $\mathrm{RP}$ & Travel mode & - & [38] \\
\hline $\begin{array}{c}\text { Prawira Fajarindra } \\
\text { Belgiawan }\end{array}$ & 2017 & Switzerland & Asian Transport Studies & Transport & 526 & SP & Travel mode & - & [39] \\
\hline Eleni Charoniti & 2017 & Netherlands & $\begin{array}{c}\text { Transportation Research } \\
\text { Procedia }\end{array}$ & Transportation & 693 & SP & Travel route & - & [40] \\
\hline Jinhee Kim & 2017 & Netherlands & Transportation Research Part A & Transportation & 955 & SP & Travel mode & $\begin{array}{l}\text { Join a car-sharing } \\
\text { organization }\end{array}$ & [41] \\
\hline Ze Wang & 2016 & China & $\begin{array}{l}\text { KSCE Journal of Civil } \\
\text { Engineering }\end{array}$ & Civil Engineering & 521 & SP & Travel route & Households & [42] \\
\hline David A. Hensher & 2016 & Australia & $\begin{array}{c}\text { Journal of Transportation } \\
\text { Engineering }\end{array}$ & $\begin{array}{c}\text { Transportation } \\
\text { Engineering }\end{array}$ & 670 & SP & Travel mode & Commuters & {$[20]$} \\
\hline Sunghoon Jang & 2016 & Netherlands & Transportation & Transportation & 354 & $\mathrm{RP}$ & Travel mode & $\begin{array}{l}\text { Representative } \\
\text { residents }\end{array}$ & [43] \\
\hline Ramin Shabanpour & - & Chicago & $\begin{array}{l}\text { Krambles Transportation } \\
\text { Scholarship Award }\end{array}$ & Transportation & 14,000 & $\mathrm{RP}$ & Travel mode & Households & [44] \\
\hline Shi An & 2015 & China & Sustainability & Environmental Sciences & 796 & $\mathrm{SP}$ & Travel mode & Residents & [45] \\
\hline Caspar G. Chorus & 2014 & Netherlands & The Journal of Choice Modelling & Choice Modelling & 550 & $\mathrm{SP}$ & Travel route & Commuters & [17] \\
\hline Carlo Giacomo Prato & 2014 & Denmark & Transportation & Transportation & 236 & $\mathrm{RP}$ & Travel route & - & [46] \\
\hline Stephane Hess & 2013 & United Kingdom & The Journal of Choice Modelling & Choice Modelling & 368 & SP & Travel mode & Commuters & [22] \\
\hline K. Parthan & 2013 & India & $\begin{array}{l}\text { Procedia-Social and Behavioral } \\
\text { Sciences }\end{array}$ & Society & 967 & $\mathrm{RP}$ & Travel mode & Workers & [28] \\
\hline Caspar G. Chorus & 2013 & Netherlands & Transportation & Transportation & 550 & SP & Travel route & Commuters & [35] \\
\hline Eran Ben-Elia & 2013 & United Kingdom & Transportation & Transportation & 49 & $\mathrm{RP}$ & Travel route & $\begin{array}{l}\text { Undergraduate } \\
\text { technion students }\end{array}$ & [47] \\
\hline Caspar G. Chorus & 2012 & Netherlands & Transportation Research Part A & Transportation & 550 & SP & Travel route & Commuters & [36] \\
\hline Carlo Giacomo Prato & 2012 & Denmark & International Conference & Travel Behaviour & 236 & $\mathrm{RP}$ & Travel route & - & [48] \\
\hline Caspar G. Chorus & 2010 & Netherlands & EJTIR & $\begin{array}{l}\text { Transport and } \\
\text { Infrastructure }\end{array}$ & 416 & SP & $\begin{array}{c}\text { Travel } \\
\text { mode/route }\end{array}$ & - & {$[37]$} \\
\hline Caspar G. Chorus & 2008 & Netherlands & Transportation Research Part B & Transportation & 264 & SP & Travel mode & Students & [4] \\
\hline
\end{tabular}


Regarding the size of the sample, the number of participants in reviewed studies varied from 49 to 14,000 , and the sample size of most papers was much more than $300(n=16)$. Only four papers collected less than 300 questionnaires. It appears that most of the papers collected data from the Stated Preference (SP) survey $(n=13)$. Only seven papers used Revealed Preference (RP) data. The dis-aggregate model can be divided into two types: RP survey and SP survey [38]. The RP survey refers to the completed selective behavior survey, and the SP survey is to select the subject's choice intention survey under the hypothesis. Compared with RP data, SP data has many advantages, such as high curability, data error adjustment, clear choice of program set, but lacks reliability. The main feature of the SP survey is that the content of the investigation has not yet occurred, so the selection conditions can be assumed based on future conditions and overcome the extrapolation problem of previous forecasting methods.

Twelve reviewed papers were divided into choice types: travel mode choice behavior $(n=8)$; and travel route choice behavior $(n=7)$; the remaining papers were about travel mode choice and travel route choice behavior. Six articles are based on commuters as the research object. A detailed review and summary will be made below about the application of the methods and theories of these literature.

\subsection{Theory Utilization}

As shown in Table 3, all the reviewed studies clearly proposed or applied a theoretical framework when analyzing the application of regret model on travel choice behavior. Among the theoretical frameworks presented in reviewed studies, every study used the RRM theory, because the formation of the regret model was rooted in RT; eleven papers based on the RUM theory; three studies proposed the Satisfaction that gives some latent variables to explain the respondents' travel choice behavior; one used Random Disutility Minimization (RDM) theory and Composite Decision Rule (CDR) theory to investigate the use of alternative behavioral frameworks; and one paper revealed the presence of Preference Heterogeneity (PH).

Table 3. Summary of theories used in selected papers.

\begin{tabular}{|c|c|c|c|c|c|c|c|}
\hline Lead Author (Year) & RRM & RUM & RDM & $\begin{array}{l}\text { Theory } \\
\text { CDR }\end{array}$ & Satisfaction & PH & References \\
\hline Sunghoon Jang (2017) & $v$ & 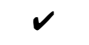 & & & & & [38] \\
\hline Prawira Fajarindra & $v$ & $\checkmark$ & & & & & [39] \\
\hline $\begin{array}{l}\text { Belgiawan (2017) } \\
\text { Eleni Charoniti (2017) }\end{array}$ & $v$ & & & & & $v$ & [40] \\
\hline Jinhee Kim (2017) & $v$ & & & & $\boldsymbol{v}$ & & [41] \\
\hline Ze Wang (2016) & $v$ & $v$ & & & & & [42] \\
\hline David A. Hensher (2016) & $v$ & $\checkmark$ & & & & $v$ & [20] \\
\hline Sunghoon Jang (2016) & $v$ & & & & & & [43] \\
\hline Ramin Shabanpour & $v$ & $v$ & & & & & [44] \\
\hline Shi An (2015) & $v$ & & & & & & [45] \\
\hline Caspar G. Chorus (2014) & $v$ & 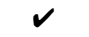 & & & & & [17] \\
\hline Carlo Giacomo Prato (2014) & $v$ & $\checkmark$ & & & & & [46] \\
\hline Caspar G. Chorus (2013) & $v$ & $v$ & & & & & [18] \\
\hline Stephane Hess (2013) & & $\checkmark$ & & & $\checkmark$ & & [22] \\
\hline K. Parthan (2013) & $v$ & $v$ & $v$ & $\checkmark$ & & & [28] \\
\hline Caspar G. Chorus (2013) & $v$ & & & & & & [35] \\
\hline Eran Ben-Elia (2013) & $v$ & v & & & & & [47] \\
\hline Caspar G. Chorus (2012) & $v$ & 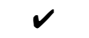 & & & 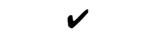 & & [36] \\
\hline Carlo Giacomo Prato (2012) & $v$ & $v$ & & & & & [48] \\
\hline Caspar G. Chorus (2010) & $v$ & v & & & & & [37] \\
\hline Caspar G. Chorus (2008) & $v$ & & & & & & [4] \\
\hline
\end{tabular}

RRM: Random Regret-Minimization; RUM: Random Utility Maximization; RDM: Random Disutility Minimization; CDR: Composite Decision Rule; PH: Preference of Heterogeneity. 
Caspar G. Chorus [36] firstly combined the RRM with the customer's satisfaction. The result indicated that the correlation of behavioral notions of choice set-desirability and choice-satisfaction correlations are rather weak. Subsequently, Stephane Hess et al. [22] used the structure of the RRM model to explain the connection of traveler's satisfaction with the travel conditions of the real world and travel choice behavior through the driving of some latent variables. Notably, the most regret-prone respondents are more likely to have aligned their real-life commute performance more closely with their hopeful values. Jinhee Kim et al. [41] enabled RRM to explain the risky alternative background of mid-term car-sharing decisions, suggesting that satisfaction can compensate expected regret. Thus, the combination of RT and customer satisfaction can help to analyze the factors comprehensively that influence factors in respondents' travel choice behavior. K. Parthan and Karthik K. Srinivasan [28] compared four alternate behavioral frameworks (RUM, RDM, RRM, CDR) to consider mode choice behavior of workers in Chennai city. The results suggest that semi-compensatory frameworks deliver a better behavior explanation than fully compensatory ones. RRM and CDR frameworks were statistically superior to RUM and RDM frameworks, and noted that the performance of CDR is better than RRM. This indicates that some attributes are evaluated based on the regret criterion and others based on utility maximization.

Since Caspar G. Chorus [4] proposed that RRM can analyze the travel choice behavior, an increasing number of studies have compared the RRM with the RUM. Sunghoon Jang et al. [38] addressed the so-called uncertainty problem due to measurement error in random utility and random regret choice models. They argued that uncertainty tends to accumulate in random regret models because this model involves a comparison of alternatives. Ze Wang et al. [42] compared RRM and RUM paradigms in emergency evacuation decision application. The estimation reveals that the regret-based model performs better than the utility-based model.

According to the research methods used in the study, a different theoretical framework can bring different research variables and parameters. Selecting one or several appropriate theories as a research basis enables the article structure to be much more systematic and organized. Additionally, they also enable the paper content to be more stringent, more persuasive and have more reference value.

\subsection{Influencing Factors}

\subsubsection{The Influencing Factors of Travel Mode Choice Behavior}

Mode choice affects the vehicular demand for travel by personal vehicle, public transit and non-motorized modes. Thus, it has significant influence on sustainability, air-quality, congestion and system operating cost, etc. The mode choice of travel behavior is affected by various factors, such as: traveler attributes and alternative specific. A summary of the attributes of travel mode choice behavior in the selected papers is shown in Table 4. 
Table 4. The attributes of travel mode choice behavior in the selected papers.

\begin{tabular}{|c|c|c|c|c|c|}
\hline \multirow{2}{*}{ References } & \multirow{2}{*}{ Pub. Year } & \multirow{2}{*}{ Lead Author } & \multirow{2}{*}{ Travel Mode } & \multicolumn{2}{|c|}{ Attributes } \\
\hline & & & & Traveler Attribute & Alternative Specific \\
\hline [38] & 2017 & Sunghoon Jang & Car, Bike, Walk & - & Travel time, Travel distance \\
\hline [39] & 2017 & Prawira Fajarindra Belgiawan & BRT, Car, Motor cycle & Gender, Age, Income & $\begin{array}{l}\text { Travel Time, Travel Cost, Waiting time, } \\
\text { Walking distance to shelter, Parking cost, } \\
\text { Easiness of parking }\end{array}$ \\
\hline [41] & 2017 & Jinhee Kim & Car, Public transport & $\begin{array}{l}\text { Gender, Age, Number of household, Education } \\
\text { level, Income }\end{array}$ & $\begin{array}{l}\text { Comfort, Safety, Accessibility (Public transport } \\
\text { (PT)), Convenience in transfer (PT), Travel } \\
\text { time, Travel cost, Parking condition (car), } \\
\text { Frequency of service (PT) }\end{array}$ \\
\hline [20] & 2016 & David A. Hensher & Bus, Train, Metro, Car & - & $\begin{array}{l}\text { Travel time, Fare, No. people standing, Egress } \\
\text { time, \% Seats occupied }\end{array}$ \\
\hline [43] & 2016 & Sunghoon Jang & Car, Bike, Walk & - & Travel time, Travel distance \\
\hline [44] & - & Ramin Shabanpour & Walk, Bike, Auto & $\begin{array}{l}\text { n Veh, Age, Tottr, n Trans Stop Origin, n Trans } \\
\text { Stop Destination, Distance Walk, Tour Purpose } \\
\text { Work, Tour Purpose Shop, Female, Income, } \\
\text { Trans Access, Trans Egress, n Transfer, Weekend }\end{array}$ & Travel Time, Travel Cost \\
\hline [45] & 2015 & Shi An & Public, Private, Shared & $\begin{array}{l}\text { Gender, Age, Education, Experience, Car } \\
\text { ownership, Kids, The elderly }\end{array}$ & Travel time, Wait time, Comfort \\
\hline [22] & 2013 & Stephane Hess & - & - & $\begin{array}{l}\text { Travel time, Fare, Crowding, Rate of delays, } \\
\text { Average length of delays, Provision of a delay } \\
\text { information, Service with different pricing }\end{array}$ \\
\hline [28] & 2013 & K. Parthan & $\begin{array}{l}\text { Two-wheeler, Car, Bus, } \\
\text { Train, Non-motorized }\end{array}$ & $\begin{array}{l}\text { Average household size, Average age of a } \\
\text { worker, Average household income }\end{array}$ & $\begin{array}{l}\text { Comfort, Safety, Reliability, Ease of train } \\
\text { access, Travel time, Travel cost }\end{array}$ \\
\hline [37] & 22011 & Caspar G. Chorus & Car, Train & - & $\begin{array}{l}\text { Expected in-vehicle, travel time, Travel time } \\
\text { uncertainty, Expected travel costs, Travel costs } \\
\text { uncertainty, Expected waiting time, Waiting } \\
\text { time uncertainty, Expected seat availability, } \\
\text { Seat availability uncertainty }\end{array}$ \\
\hline [4] & 22008 & Caspar G. Chorus & Car, Train & Gender, Age, Completed education & $\begin{array}{l}\text { Travel time, Main out-of-home activity, Travel } \\
\text { cost, Public transport (PT), Season ticket, Car } \\
\text { availability, Regret threshold }\end{array}$ \\
\hline
\end{tabular}


There are six articles that take into account traveler attributes (socio-demographics) and alternative specific (such as, travel time, travel cost, comfort, safety, etc.) simultaneously when analyzing the choice of travel mode. Sunghoon Jang et al. [38] used the sub-data that include two levels of service variables (travel time and travel distance) for three mode choice alternatives (car, bike, and walk). Prawira Fajarindra Belgiawan et al. [39] gave sets of scenarios where they need to choose between four alternatives modes (BRT, feeder, car and motorcycle). All of the parameter estimates (time and cost) are significant ( $p$ value $<0.01$ ) with expected sign. Jinhee Kim et al. [41] examined the effects of latent satisfaction with current mobility options and uncertainty underlying car-sharing decisions. This study identified that the latent satisfactions are a function of the traveler attributes and alternative specifically affecting the degree of satisfaction with current mobility options (car-ownership and most frequent trip). The results show that satisfaction significantly affects the car-sharing decision and car availability has a significant effect on the likelihood of joining a car-sharing organization. Therefore, the satisfaction indicators play an important role in the study of travel mode choice behavior. A number of key variables (socio-demographic and economic attributes) were examined to specify the corresponding utility/regret functions by Ramin Shabanpour [44]. It shows that the travel time and travel cost are two essential factors when we analyze travel mode choice behavior based on RRM. Shi An et al. [45] integrated regret psychology to travel mode choice for a transit-oriented evacuation strategy. They found that the most sensitive attributes are travel time and comfort and also pointed out that travel time should be considered as one of the key determinants for evacuation strategy development. K. Parthan et al. [28] suggested that comfort in personal vehicles, reliability in public transport and safety in the bus are important factors. The results show that the effect of subjective factors have a greater influence on travel mode choice than the most obvious determinants of choice. Hence, researchers should pay attention to the measurement of subjective factors when they study travel choice behavior. Scholars rarely mentioned the parameter of regret threshold for travel mode choice. Caspar G. Chorus et al. [4] pointed out the the higher individual's regret threshold, the less he or she is prone to regret. So, different individuals have different regret-thresholds.

The other four papers did not consider traveler attributes. They put the focus on alternative specifics. David A. Hensher [20] mentioned that several attributes vary across respondents with the model alternatives and exposed the presence of preference heterogeneity which pivoted around a reference trip that a sampled individual had recently travelled. David A. Hensher investigated the crowding by the number of seated and standing. This indirect method of measurement is worth learning when we measure some variables. He suggested that some social-economic variables are not statistically significant in any of the modal alternatives; on the contrary, some observation variables have great influence on the model alternatives when we choose a suitable model to evaluate the samples. Sunghoon Jang et al. [43] incorporated psycho-physical mapping into random regret choice models. In the second case, they studied some factors that affect the choice of travel mode. The power coefficient for travel time and distance is somewhat higher in the logarithmic specification. The newly advised RRM, combining a non-linear representation of perception, achieves significant improvements in goodness-of-fit over the original regret formulations. Six factors were selected to characterize the commute by Stephane Hess et al. [22]. They were not mentioned in other papers. Caspar G. Chorus. [37] analyzed the influencing factors mainly from two aspects, the expected value and the true value. The logic of considering influencing factors requires clarification, so it is worth examining.

\subsubsection{The Influencing Factors of Travel Route Choice Behavior}

The importance of travel route choice has a direct influence on the reliability of traffic assignment in the four stages model of traffic planning. It has a great significance in the field of traffic planning. The travel route choice behavior likes travel mode choice behavior that is affected by various factors. A summary of the attributes of travel route choice behavior in the selected papers is shown in Table 5 . 
Table 5. The attributes of travel route choice behavior in the selected papers.

\begin{tabular}{|c|c|c|c|c|}
\hline \multirow{2}{*}{ References } & \multirow{2}{*}{ Pub. Year } & \multirow{2}{*}{ Lead Author } & \multicolumn{2}{|c|}{ Attributes } \\
\hline & & & Traveler Attribute & Alternative Specific \\
\hline [40] & 2017 & Eleni Charoniti & $\begin{array}{l}\text { Gender, Age, Education, } \\
\text { Driving licence, Mainly used } \\
\text { means of transport }\end{array}$ & $\begin{array}{l}\text { Time pressured, Anxious and } \\
\text { worried, Regret averse }\end{array}$ \\
\hline [42] & 2016 & Ze Wang & $\begin{array}{l}\text { Gender, Age, Education, Kids, } \\
\text { The elderly, Experience }\end{array}$ & $\longrightarrow$ \\
\hline [17] & 2014 & Caspar G. Chorus & Gender, Age, Education level & $\begin{array}{l}\text { Average travel time, Travel } \\
\text { costs, Travel time variability, } \\
\text { Percentage of travel time in } \\
\text { congestion }(\%),\end{array}$ \\
\hline [46] & 2013 & Carlo Giacomo Prato & - & $\begin{array}{l}\text { Cost of travel, Travel time, Right } \\
\text { turns, Left turns, Traffic lights }\end{array}$ \\
\hline [18] & 2013 & Caspar G. Chorus & Gender, Age, Education level & $\begin{array}{l}\text { Average travel time, Travel } \\
\text { costs, Percentage of travel time } \\
\text { in congestion }(\%) \text {, Number of } \\
\text { traffic fatalities per year }\end{array}$ \\
\hline [35] & 2013 & Caspar G. Chorus & - & $\begin{array}{l}\text { Average travel time, Percentage } \\
\text { of travel time in congestion (\%), } \\
\text { Travel time variability, Travel } \\
\text { costs }\end{array}$ \\
\hline [47] & 2012 & Eran Ben-Elia & $\begin{array}{l}\text { Gender, Age, Drivers licence, } \\
\text { Car availability, Employment, } \\
\text { Family composition, Car Use }\end{array}$ & $\begin{array}{l}\text { Travel mode to campus, } \\
\text { Travel time }\end{array}$ \\
\hline [36] & 2012 & Caspar G. Chorus & Gender, Age, Education level & $\begin{array}{l}\text { Average travel time, Travel } \\
\text { costs, Percentage of travel time } \\
\text { in congestion (\%), Number of } \\
\text { traffic fatalities per year, } \\
\text { Desirability, Satisfaction }\end{array}$ \\
\hline [48] & 2012 & Carlo Giacomo Prato & - & $\begin{array}{l}\text { Cost of travel, Travel time, Right } \\
\text { turns, Left turns, Traffic lights }\end{array}$ \\
\hline
\end{tabular}

It is notable that these three papers were all undertaken by Caspar G. Chorus and used the same sample $[17,35,36,46]$. So, the research variables of the three papers are similar, such as socio-demographics made up of gender, age and education level. Caspar G. Chorus assumed three different routes that differed in terms of the following four attributes, with three levels each: average travel time, percentage of travel time spent in congestion, travel time variability or number of traffic fatalities per year, and travel costs. Obviously, if you can pay higher travel costs, the average travel time will be relatively shorter, the percentage of travel time spent in congestion will be lower, the number of traffic fatalities per year will be less and the travel time variability will be smaller. There is a deficiency in these two articles when they consider the influencing factors without taking into account the psychological factors. In the fourth paper [36], Caspar G. Chorus studied to what extent they considered the choice set to be desirable or to what extent they were satisfied with the chosen alternative by asking participants to make a stated route choice experiment when they experienced each choice based Logsum measure (Logsum is often interpreted as a measure of choice set-desirability, and also by the increasing academic interest in modeling and understanding travelers' satisfaction with chosen alternatives) [18]. The result shows that 'desirability' and 'satisfaction' have a different meaning from the respondents' perspective.

Eleni Charoniti et al. [40] attempted to define class membership as a function of personality traits, decision context and socio-demographic characteristics of the sample, which seems to enhance the understanding of the choices made. Ze Wang et al. [42] noted that traveler attributes will affect the people's evacuation route choices and should be included as interaction terms. Carlo Giacomo Prato $[46,48]$ estimated the following attributes in the utility and the regret functions: the cost of travel, travel time, right turns, left turns and traffic lights. Eran Ben-Elia [47] considered nine influencing 
factors for the travel route choice behavior. It is worth noting that his analysis of the impact of travel mode on travel route choice, as the travel mode and the travel route choice is closely related.

A better behavioral understanding by estimating suitable factors can lead to more accurate travel choice forecasts and has important implications for evaluating urban transport plans and policies.

\subsection{Methodology}

A total of fourteen literatures in Table 6 used eight statistical methods based on the regret model to explore the relationship between the influencing factors and travel behavior. Three papers did not use statistical methods, only using RRM model and RUM model to explain the influence of factors on travel choice behavior.

Table 6. Summary of statistical methods used in selected papers.

\begin{tabular}{|c|c|c|c|c|c|c|c|c|c|}
\hline \multirow{2}{*}{ Lead Author (Year) } & \multicolumn{8}{|c|}{ Statistical Methods } & \multirow{2}{*}{ References } \\
\hline & MNL & MMNL & MIMIC & ML & $\mathbf{L}$ & PCL & $\mathrm{HCM}^{1}$ & LCM & \\
\hline Sunghoon Jang (2017) & & & & & & & & & [38] \\
\hline Prawira Fajarindra Belgiawan (2017) & $\boldsymbol{v}$ & & & & & & & & [39] \\
\hline Eleni Charoniti (2017) & & & & $\checkmark$ & & & & $\checkmark$ & [40] \\
\hline Jinhee Kim (2017) & & & $\boldsymbol{\sim}$ & & & & $\checkmark$ & & {$[41]$} \\
\hline Ze Wang (2016) & & & & & & & $\checkmark$ & & [42] \\
\hline David A. Hensher (2016) & $\boldsymbol{V}$ & $\boldsymbol{V}$ & & $\checkmark$ & & & & & [20] \\
\hline Sunghoon Jang (2016) & & & & & $\checkmark$ & & & & [43] \\
\hline Ramin Shabanpour & $\boldsymbol{v}$ & & & & & & & & [44] \\
\hline Shi An (2015) & & & & $\checkmark$ & & & $\checkmark$ & & {$[45]$} \\
\hline Caspar G. Chorus (2014) & & & & & & & & & [17] \\
\hline Carlo Giacomo Prato (2014) & $\boldsymbol{v}$ & & & & & & & & [46] \\
\hline Caspar G. Chorus (2013) & & & & & & & $\boldsymbol{\sim}$ & & [18] \\
\hline Stephane Hess (2013) & $\boldsymbol{v}$ & & & & & & $\boldsymbol{\nu}$ & & [22] \\
\hline K. Parthan (2013) & $\boldsymbol{V}$ & & & & & & & & [28] \\
\hline Caspar G. Chorus (2013) & $\checkmark$ & & & & & & & & [35] \\
\hline Eran Ben-Elia (2013) & & & & $\checkmark$ & & & & & [47] \\
\hline Caspar G. Chorus (2012) & $\boldsymbol{\nu}$ & & & & & & & & [36] \\
\hline Carlo Giacomo Prato (2012) & $\checkmark$ & & & & & $\checkmark$ & & & [36] \\
\hline Caspar G. Chorus (2010) & $\boldsymbol{V}$ & & & & & & & & [37] \\
\hline Caspar G. Chorus (2008) & & & & $\checkmark$ & & & & & [4] \\
\hline
\end{tabular}

Ten of the studies used a Multinomial Logit (MNL) model to highlight the advantages of using RRM model to analyze travel choice behavior. Rock of RUM, which maps to the fully compensatory decision rule, leads to the restrictive IIA assumption [17]. This may cause some unobservable variables to be violated by taking a different travel route or travel mode. However, because of the specification of the regret function that is easily estimable by using conventional discrete choice software packages in the research field. It is worth noting that the RRM-based MNL-model does not exhibit the property of IIA, even with the assumption of IID error terms [22]. Therefore, the selection of MNL provides a decent service for the estimation of the RRM model.

A Hybrid Choice Model $\left(\mathrm{HCM}^{1}\right)$ was applied in five articles that generally integrate latent variables and discrete choice models into a structure. $\mathrm{HCM}^{1}$ not only explains the relationship between variables and variables, but also explains the correlation between variables and travel behavior. The parameters are estimated based on the maximum likelihood method using BIOGEME [49]. Eleni Charoniti et al. [40] pointed out that Latent Class Model (LCM) analysis allows the identification of more homogeneous latent classes, with different regret parameters. Once the regret function of each choice for each latent class and the probability of belonging to each class are known, choice probabilities equal the weighted sum of choice probabilities across the classes with the class allocation probabilities being used as weights.

Seven more papers used Mixed Multinomial Logit (MMNL) model, Multiple Indicators Multiple Causes (MIMIC) model, Mixed Logit (ML) model, Logit (L) model, Paired Combinatorial Logit (PCL) model to estimate the relationship between the influencing factors and the choice behavior of each 
travel mode. The advantage of the MIMIC model is that it can consider the internal mechanism of each factor [41].

\subsection{Model Comparison}

Comparing the regret model and utility model, we can see that the two models are similar in structure. As shown in Table 7, the former inherits the description form of the function under the utility criterion and uses the random parts to describe the random regret. From the modeling concept, the utility perspective is more concerned with the total whether the utility is the largest, and the effect of the effect of observation is not detailed enough. The regret theory makes up for this deficiency, assuming that the option has a regrettable value in the attribute through comparing of different attributes choices that bring regret. Because the probability of regret model is expressed as a convex function, it shows that the attributes have a semi-compensatory effect on the total regret, that is, the serious regret of some attributes do not be completely compensated by the weak regret of other attributes, which is more semi-compensated with the decision-making behavior in reality. K. Parthan and Karthik K. Srinivasan [28] suggest that semi-compensatory frameworks deliver a better behavior explanation than fully compensatory ones.

Table 7. Compare the model features between RRM model and RUM model.

\begin{tabular}{|c|c|c|}
\hline Model. & RRM Model & RUM Model \\
\hline Theory & RT & UT \\
\hline Target & $\begin{array}{l}\text { Choosing the minimum regret in the } \\
\text { alternatives }\end{array}$ & $\begin{array}{l}\text { Choosing the maximum utility in the } \\
\text { alternatives }\end{array}$ \\
\hline Criterion & $\begin{array}{l}\text { Regret function, describing the regret when the } \\
\text { decision maker made a choice }\end{array}$ & $\begin{array}{l}\text { Utility function, describing the satisfaction } \\
\text { when the decision maker made a choice }\end{array}$ \\
\hline Strategy & Semi-compensatory & Compensatory \\
\hline Structure & $\begin{array}{l}R R_{i}=R_{i}+\varepsilon_{i} \\
=\sum_{j \neq i} \sum_{m} \ln \left\{1+\exp \left[\beta_{m} \times\left(x_{j m}-x_{i m}\right)\right]\right\}+\varepsilon_{i}\end{array}$ & $\begin{array}{l}R U_{i}=U_{i}+\varepsilon_{i} \\
=\sum_{m} \beta_{m} \times x_{i m}+\varepsilon_{i}\end{array}$ \\
\hline Probability calculation & $P_{i}=P\left(R R_{i}<R R_{j}, \forall j \neq i\right)$ & $P=P\left(R U_{i}>R U_{j}, \forall j \neq i\right)$ \\
\hline
\end{tabular}

Table 8 compares the model fit between RRM model and RUM model. David A. Hensher et al. [20] aimed to establish if there is an improvement in overall statistical fit when migrating from RUM to RRM under both MNL $(0.4440,0.4436)$ and MMNL $(0.549,0.551)$. The overall goodness of fit of the MMNL models is significantly better than the MNL models. A model fit comparison showed that the RRM model empirically outperforms the standard RUM model. K. Parthan et al. [28] found that the models representing semi-compensatory decision rule (0.492) outperform the fully compensatory decision rule $(0.491)$ model. Most scholars $[36,37]$ used R-square to measure the overall fitness based on the RUM models and RRM models. In terms of the comparison between RRM and RUM's linear-additive MNL-model, it appeared that the RRM-model fits the data slightly better than its utilitarian counterpart. For the goodness of fit of the models, the likelihood ratio index is calculated based on the statistic suggested by McFadden [50]. This index, although different in concept, is analogous to the R-square in linear regression models. The result $(60.5 \%, 63.1 \%)$ [44] showed that the likelihood ratio for regret-based MNL is slightly higher.

Through comparing and analyzing in terms of what features of the modes and how best the models fit the data, the superiority of RRM model in explaining travel behavior was demonstrated. 
Table 8. Compare the model fit between RRM model and RUM model.

\begin{tabular}{cccc}
\hline Model Fit & RUM Model & RRM Model & References \\
\hline Adj. Rho-square & 0.643 & 0.787 & {$[42]$} \\
Pseudo R $^{2}$ & 0.4440 & 0.4436 & {$[20]$} \\
Pseudo R $^{2}$ & 0.549 & 0.551 & {$[20]$} \\
Likelihood Ratio Index & $60.5 \%$ & $63.1 \%$ & {$[44]$} \\
Adj. Rho-square & 0.321 & 0.323 & {$[17]$} \\
Adj. Rho-square & 0.371 & 0.371 & {$[17]$} \\
$p^{2}$ & 0.491 & 0.492 & {$[28]$} \\
Rho-square & 0.34 & 0.34 & {$[36]$} \\
Rho-square & 0.433 & 0.440 & {$[37]$} \\
\hline
\end{tabular}

\section{Quality of Reviewed Studies}

The quality of reviewed studies is varied with scores ranging from 2 to 13 , as shown in Table 9 . According to Table 9, all studies applied a cross sectional study design to carry out the survey. Sixteen studies' $(75.00 \%)$ sample size was bigger than 300 , and only one paper used 49 records to study the travel route choice based on RRM model [47]. Most studies (70.00\%) had identified the study objects. All the articles are based on the RT to analyze the travel mode/route choice behavior, of which $60.00 \%$ compared this with other theoretical models. Moreover, 17 studies used statistical models. Many papers $(95 \%)$ tested the goodness of fit of the model. Most studies $(75.00 \%)$ had a parameter selection reliability testing. We can see from Table 8 , most of the articles $(65.00 \%)$ only analyze manifest variables or only include latent variables. We can conclude that not every paper covered all points, so there is still much room for improvement to study the travel mode/route choice behavior.

Table 9. Distribution of quality characteristics across reviewed studies.

\begin{tabular}{|c|c|c|c|c|}
\hline Criterion & Description & Score & $n$ of Studies & Percentage \\
\hline \multicolumn{5}{|c|}{ Assessing data collecting methodological quality } \\
\hline \multirow{2}{*}{ Study design } & Experimental, case control, or longitudinal study & 2 & 0 & $0.00 \%$ \\
\hline & Cross-sectional study & 1 & 10 & $100.0 \%$ \\
\hline \multirow{3}{*}{ Adequate sample size selection } & Large $(>300)$ & 3 & 16 & $80.00 \%$ \\
\hline & Medium (100-300) & 2 & 3 & $15.00 \%$ \\
\hline & Small $(<100)$ & 1 & 1 & $5.00 \%$ \\
\hline \multirow{2}{*}{ Indicating the study object } & Included & 1 & 14 & $70.00 \%$ \\
\hline & Not included & 0 & 6 & $30.00 \%$ \\
\hline \multicolumn{5}{|c|}{ Assessing theory utilization } \\
\hline \multirow{2}{*}{ Application of regret theory } & Included & 1 & 16 & $100.00 \%$ \\
\hline & Not include & 0 & 0 & $0.00 \%$ \\
\hline \multirow{2}{*}{ Comparative analysis } & Included & 1 & 12 & $60.00 \%$ \\
\hline & Not included & 0 & 8 & $40.00 \%$ \\
\hline \multicolumn{5}{|c|}{ Assessing methods utilization } \\
\hline \multirow{2}{*}{$\begin{array}{l}\text { Application of statistical } \\
\text { methods }\end{array}$} & Included & 1 & 17 & $85.00 \%$ \\
\hline & Not included & 0 & 3 & $15.00 \%$ \\
\hline \multirow{2}{*}{ Goodness of fit test } & Tested & 1 & 19 & $95.00 \%$ \\
\hline & Not tested & 0 & 1 & $5.00 \%$ \\
\hline \multirow{2}{*}{$\begin{array}{l}\text { Parameter selection } \\
\text { reliability testing }\end{array}$} & Tested & 1 & 15 & $75.00 \%$ \\
\hline & Not tested & 0 & 5 & $25.00 \%$ \\
\hline \multicolumn{5}{|c|}{ Assessing comprehensiveness of factors } \\
\hline \multirow{3}{*}{ Analysis of influencing factors } & Include manifest variables and latent variables & 2 & 7 & $35.00 \%$ \\
\hline & $\begin{array}{l}\text { Only included manifest variables or only } \\
\text { included latent variables }\end{array}$ & 1 & 13 & $65.00 \%$ \\
\hline & Not included & 0 & 0 & $0.00 \%$ \\
\hline
\end{tabular}




\section{Discussion}

The aim of this systematic literature review was to summarize and critically assess the current literature on using regret model to analyze travel mode choice and travel route choice behavior. To the best of our knowledge, this may be the first systematic review evaluating the quality of empirical studies involving RRM model on travel mode choice behavior and travel route choice behavior.

\subsection{Empirical Issues}

From the above analysis, we can conclude that it is necessary to expand the application of the RRM model on travel mode and travel route choice behavior. Most of the studies come from the developed countries in Table 1. In order to gain a better understanding of the application of the RRM on travel behavior, it is necessary to extend the study to other regions such as Asia and Africa. When we use the RRM model to analyze the travel behavior of a particular population in different regions, how to establish effective guidance measures through the prediction variables of travel mode or travel route choice behavior is more important. It can make the choice of travel mode develop a safe, green and sustainable way. Meanwhile, it can guarantee that the choice of travel route avoids urban congestion and reduce the burden on urban roads. The research in this area needs to be further strengthened. Moreover, most of the studies are based on cross-sectional data from which is impossible to infer the quantitative impact of the findings on future policies or guidance measures, suggesting that a longitudinal survey should be carried out by research. Through model predictions and discussions, it should be examined whether the conclusions can lead to a green and effective direction of travel behavior.

\subsection{Theoretical Issues}

In the field of travel behavior, a variety of theoretical frameworks has been the first step in the successful development of behavioral interference or guidance measures. The significance of the rigorous evaluation of the existing literature on travel behavior research is to distinguish between those who are not strict in the design of the survey, those where the use of the model method is not entirely correct, and those where there is no theoretical framework to support the study. In addition to these theoretical frameworks mentioned in twenty papers, the researchers put forward a number of theoretical models used to describe, predict, explain and change the individual's travel behavior, such as: the Theory of Reasoned Behavior (TRB), Social Cognitive Theory (SCT), the Theory of Plan Behavior (TPB), Self-Efficacy Theory (SET), Norm activation theory (NAT), Stage Model of Self-Regulated Behavioral Change (SSBC), Health Action Process Approach (HAPA), the Transtheoretical Model (TTM), etc. In the field of other behavioral research, these psychological theories, which are used to predict, explain and change individual behaviors, are summarized into two categories: Continuity Theory Model (CTM) and Stage Theoretical Model (STM). As Figure 2 shows, if the future research can combine these theories with the RRM to consider more psychological variables, this could explain the characteristics of travel behavior more specifically. Therefore, it is essential to establish a theoretical framework for an empirical study of travel behavior. 


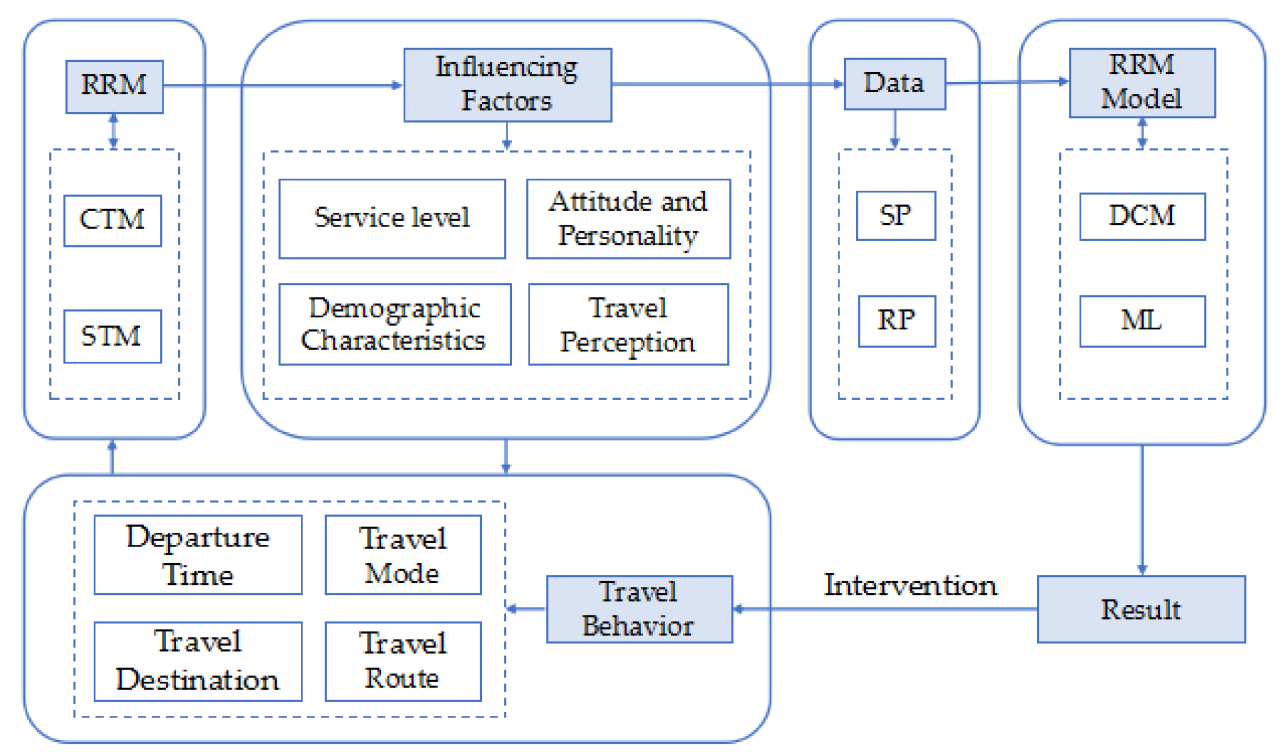

Figure 2. Research framework based on RRM.

\subsection{Factor Issues}

The influencing factors extracted need to be measured according to the established theoretical framework and combined with reality. More and more scholars had added psychological factors to the study of shape and behavior. In the following discussion, we will mention various methods, including Latent Variable Models (LVM), Hidden Class Models $\left(\mathrm{HCM}^{2}\right)$, Structural Equation Models (SEM) and Integrated Hybrid Models (IHM), which have extended the factors that affect travel choice behavior to psychology field [51]. This expansion will enable traffic planners to begin a more comprehensive consideration of travel behavior factors when they make these demand forecasts. Generally, the influencing factors of travel behavior are divided into four categories: service level, demographic characteristics, attitude and personality, and travel perception. Service level and demographic characteristics are travel attributes and travelers' characteristics, all belonging to observable variables. Travel perception is actually the effect of travel attributes on the individual psychology of travelers. However, in general, the travel perception and attitude and personality, as the traveler's psychological factors, are not directly observed. The purpose of the study is not limited to understanding and analyzing the influence extent of various factors on travel behavior. The ultimate goal is to identify important beliefs that affect variables. We can see from Figure 2 that these factors can play a role in intervention in the future improvement measures. Determining the travel behavior of travelers with different characteristics of the behavioral interference key factor, providing theoretical support for the demand management strategy and promoting urban traffic trends towards safe, effective and sustainable development.

\subsection{Methodological Issues}

In order to accurately measure the impact of various factors on travel behavior, we need to build a mathematical model that matches them. Through summing and commenting on the statistical methods of the twenty articles, we can note that in the context of RRM, the study of travel behavior commonly used data analysis methods are linear correlation analysis and linear regression analysis. Linear correlation analysis pointed out the statistical relation between two random variables, and their correlation coefficient could not reflect the causality between the single index and the whole. Because of collinearity, linear regression may lead to unexplained data analysis such as the negative correlation between single index and overall. Jinhee Kim [41] made an important contribution by using MIMIC model to introduce socio-economic state variables and psychological variables into the model, 
explaining the interrelationships of the factors and the causal relationship between the factors. In the present study, there is little research using the Structural Equation Model (SEM) to explain the causal relationship between the various latent variables based on the RT. The SEM is a method of establishing, estimating and examining causal relationship model. The model contains observable variables and potential variables that cannot be observed directly. In general, SEM can replace multiple regression, route analysis, factor analysis, and covariance analysis and clearly analyze the effects of individual indexes on the population and the relationships among individual indexes. If psychometric indicators and potential influencing factors are introduced into the discrete selection model based on RT, the model can describe the more realistic travel decision behavior. It is also possible to establish an RRM model based on Nested Logit (NL), which obtains an independent irrelevant assumption between relaxation solutions, and effectively captures and characterizes the behavior of travel choice behavior. As showed in the Figure 2, researchers can broaden their minds to combine regret models with LVM, SEM, $\mathrm{HCM}^{2}$ and IHM, which could obtain the optimal result.

In addition, Machine Learning (ML) is a method that can be used to solve the optimization problem. For instance, Craig D'Souza et al. [52] concluded that the Artificial Immune System (AIS) method effectively tackles this optimization problem by providing us with optimal solutions. Daisik Nam et al. [53] developed such a choice model with a structure that is appropriate for the travel mode choice problem, and demonstrate the success of the model using an available dataset, so that the traffic management department, the safety management department and other relevant policy management departments will provide safe and effective interventions into future travel behavior.

\subsection{Limitations and Strengths}

The limitations of this review should be considered when explicating the current results. In the first place, the eligible papers must be published in English, which kept relevant literature published in other languages from being selected. Secondly, all included studies involving travel mode/route choice behavior were cross-sectional, such that it was not possible to determine changes over time in travel patterns. This study had two strengths. Firstly, all articles were rigorously screened based on the aforementioned well-defined inclusion/exclusion criteria in seven databases. Secondly, the quality of the articles included was evaluated in a standardized way.

\section{Conclusions}

The studies reviewed in this paper are from seven important databases through in-depth and detailed searching, thus positioning the research literature, and through the development of a clear screening mechanism to sort out the literature. A standardized and portable document quality assessment system is used to evaluate the retrieved literature, which is helpful to understand the current research level on travel mode and travel route choice behavior by using the RRM model.

This paper makes a comprehensive review and discussion for these sixteen empirical studies on the travel mode and travel route choice behavior from four main aspects: (1) empirical issues-the current situation of travel mode choice and travel route choice behavior based on regret model was understood; (2) influencing factors-a better behavioral understanding estimating suitable factors can lead to more accurate travel choice forecasts and has important implications for evaluating sustainable urban transport plans and policies; (3) theory utilization—different theoretical framework can bring different research variables and parameters. Selecting one or several appropriate theories as a research basis enables the article structure to be more systematic and organized; (4) application of mathematical methods-applying a suitable mathematical model can not only accurately analyze the correlation between variables, but also obtain rigorous research results. At the end of the article, 16 articles were evaluated for objective quality and it was found that no paper covered all points; therefore, there is still much room for improvement to study the travel mode and travel route choice behavior.

Compared with the RUM, the RRM has three advantages: (1) The RRM model features logit choice probabilities and is easily estimable by using conventional discrete choice software packages in 
the research field; (2) the RRM model does not exhibit the property of independence from irrelevant alternatives (IIA), even with the assumption of IID error terms; and (3) the RRM uses its utilitarian counterpart to model fit with choice. Therefore, RRM plays an important role in travel choice behavior. Through objectively evaluating the performance advantages of the regret model in the field of travel choice behavior by summarizing the papers about travel mode and travel route choice, the results indicate that the RRM model can reflects the influence degree of each factor on the travel choice behavior and makes a significant contribution to making traffic demand analysis more accurate. Search methods and review results in this paper provide the convenience and reference to scholars of related fields in the future research and develop novel strategies to promote the sustainable traffic system in the future.

\section{Future Works}

This paper reviewed and analyzed travel mode choice and travel route choice behavior based on RRM, which demonstrates the superiority of the RRM model in explaining travel behavior. The future research framework based on RRM is shown in Figure 2; if the future research can combine the CTM and STM with the RRM and consider more psychological variables, this will be able to more specifically explain the characteristics of travel behavior. Secondly, it is also possible to establish a regret model based on NL, which obtains an independent irrelevant assumption between relaxation solutions, and effectively capture and characterize the behavior of travel choice behavior. Then, the ML can also be used to analyze the data in the RRM. Finally, the choices of departure time and travel destination are also two important parts of travel decision-making that are interrelated and mutually restricted to travel mode and travel route choice. Thus, if future research could summarize and review these related studies of four aspects, it would make a significant contribution to travel choice behavior.

Acknowledgments: This research was supported by "Jiangsu Province Six Personnel Peaks Project", (No 2015JY025), "the Natural Science Foundation of Jiangsu Province", (No BK20160512), "the Humanity and Social Science Youth Foundation of Ministry Education of China", (No 16YJCZH027) and "the Social Science Foundation of Jiangsu Province", (No 15GLC004).

Author Contributions: Peng Jing and Mengxuan Zhao conceived the conception and conducted data collection; Meiling He and Long Chen screened and analyzed eligible papers carefully; Mengxuan Zhao wrote the manuscript. All authors have read and approved the final manuscript.

Conflicts of Interest: The authors declare no conflict of interest.

\section{References}

1. Richardson, A.J. Behavioural Considerations in Transport Modelling; Workshop on Measuring Social Behaviour in Road Research: Melbourne, Australia, 1980.

2. Manski, C.F. The structure of random utility models. Theory Decis. 1977, 8, 229-254. [CrossRef]

3. Marschak, J. Binary-Choice Constraints and Random Utility Indicators; Springer: Dordrecht, The Netherlands, 1960; pp. 312-329.

4. Chorus, C.G.; Arentze, T.A.; Timmermans, H.J.P. A Random Regret-Minimization model of travel choice. Transp. Res. Part B 2008, 42, 1-18. [CrossRef]

5. Bell, D.E. Regret in Decision Making under Uncertainty. J. Op. Res. 1982, 30, 961-981. [CrossRef]

6. Loomes, G.; Sugden, R. Regret Theory: An Alternative Theory of Rational Choice Under Uncertainty. Econ. J. 1982, 92, 805-824. [CrossRef]

7. Fishburn, P.C. Nontransitive measurable utility. J. Math. Psychol. 1982, 26, 31-67. [CrossRef]

8. Kahneman, D.; Tversky, A. Prospect theory: An analysis of decision under risk. Econometrica 1979, 47, 263-291. [CrossRef]

9. Chorus, C.; Arentze, T.A.; Timmermans, H.J.P. Comparison of Regret Minimization and Utility Maximization in the Context of Travel Mode Choices. Zool. J. Linn. Soc. 2008, 31, 14-30.

10. Caspar, C. Random Regret Minimization: An Overview of Model Properties and Empirical Evidence. Transp. Rev. 2012, 32, 75-92. 
11. van Dijk, W.W.; Zeelenberg, M.; van der Pligtc, J. Blessed are they who expect nothing: Avoiding disappointment and lowering expectations. J. Econ. Psychol. 2003, 24, 505-516. [CrossRef]

12. Emilio, F.; John, R.C.; Janet, B. A Structural Modeling Examination of the Executive Decline Hypothesis of Cognitive Aging Through Reanalysis of Crawford et al.'s (2000) Data. Aging Neuropsychol. Cognit. 2002, 9 , 231-249.

13. Dhar, R.; Simonson, I. The Effect of the Focus of Comparison on Consumer Preferences. J. Mark. Res. 1992, 29, 430-440. [CrossRef]

14. Schölkopf, B.; Warmuth, M.K. Computational Learning Theory and Kernel Machines. In Proceedings of the 16th Annual Conference on Computational Learning Theory and 7th Kernel Workshop, COLT/Kernel 2003, Washington, DC, USA, 24-27 August 2003.

15. Chorus, C.G.; Jong, G.C.D. Modeling experienced accessibility for utility-maximizers and regret-minimizers. J. Transp. Geogr. 2011, 19, 1155-1162. [CrossRef]

16. Kaplan, S.; Prato, C.G. The application of the random regret minimization model to drivers' choice of crash avoidance maneuvers. Transp. Res. Part F 2012, 15, 699-709. [CrossRef]

17. Chorus, C.G. Benefit of adding an alternative to one's choice set: A regret minimization perspective. J. Choice Model. 2014, 13, 49-59. [CrossRef]

18. Chorus, C.G. A Generalized Random Regret Minimization model. Transp. Res. Part B 2014, 68, $224-238$. [CrossRef]

19. Chorus, C.; Cranenburgh, S.V.; Dekker, T. Random regret minimization for consumer choice modeling: Assessment of empirical evidence. J. Bus. Res. 2014, 67, 2428-2436. [CrossRef]

20. Hensher, D.A.; Greene, W.H.; Ho, C.Q. Random Regret Minimization and Random Utility Maximization in the Presence of Preference Heterogeneity: An Empirical Contrast. J. Transp. Eng. 2016, 142, 04016009. [CrossRef]

21. Chorus, C.G.; Koetse, M.J.; Hoen, A. Consumer preferences for alternative fuel vehicles: Comparing a utility maximization and a regret minimization model. Energy Policy 2013, 61, 901-908. [CrossRef]

22. Hess, S.; Stathopoulos, A. A mixed random utility-Random regret model linking the choice of decision rule to latent character traits. J. Choice Model. 2013, 9, 27-38. [CrossRef]

23. Mark, V. Preferred Reporting Items for Systematic Reviews and Meta-Analyses. Oncol. Nurs. Forum 2015, 42, 552-554.

24. Lu, W.; McKyer, E.L.; Lee, C.; Goodson, P.; Ory, M.G.; Wang, S. Perceived barriers to children's active commuting to school: A systematic review of empirical, methodological and theoretical evidence. Int. J. Behavi. Nutr. Phys. Act. 2014, 11, 1-20. [CrossRef] [PubMed]

25. Moher, D.; Liberati, A.; Tetzlaff, J.; Altman, D.G.; The PRISMA Group. Preferred Reporting Items for Systematic Reviews and Meta-Analyses: The PRISMA Statement. Rev. Esp. Nutr. Hum. Diet. 2014, 18, e123.

26. Zhang, J.; Goodson, P. Predictors of international students' psychosocial adjustment to life in the United States: A systematic review. Int. J. Intercult. Relat. 2011, 35, 139-162. [CrossRef]

27. Tae-Hyoung, T.G. The relationships between land use measures and travel behavior: A meta-analytic approach. Transp. Plan. Technol. 2013, 36, 413-434.

28. Parthan, K.; Srinivasan, K.K. Investigation of Alternate Behavioural Frameworks for Mode Choice Decisions of Workers in Chennai City. Procedia Soc. Behav. Sci. 2013, 104, 573-582. [CrossRef]

29. Bunting, B. Review of Latent variable and latent structure models. Br. J. Math. Stat. Psychol. 2003, 10, 165-174.

30. Leong, W.; Hensher, D.A. Embedding decision heuristics in discrete choice models: A review. J. Transport Reviews 2012, 32, 313-331.

31. Rasouli, S.; Timmermans, H. Specification of regret-based models of choice behaviour: Formal analyses and experimental design based evidence. Transportation 2017, 44, 1555-1576. [CrossRef]

32. Cranenburgh, S.V.; Guevara, C.A.; Chorus, C.G. New insights on random regret minimization models. Transp. Res. Part A 2015, 74, 91-109. [CrossRef]

33. Hess, S.; Beck, M.J.; Chorus, C.G. Contrasts between utility maximisation and regret minimisation in the presence of opt out alternatives. Transp. Res. Part A 2014, 66, 1-12. [CrossRef]

34. Mai, T.; Bastin, F.; Frejinger, E. On the similarities between random regret minimization and mother logit: The case of recursive route choice models. J. Choice Model. 2017, 23, 21-33. [CrossRef] 
35. Chorus, C.G. An empirical comparison of travel choice models that capture preferences for compromise alternatives. Transportation 2013, 40, 549-562. [CrossRef]

36. Chorus, C.G. Logsums for utility-maximizers and regret-minimizers, and their relation with desirability and satisfaction. Transp. Res. Part A 2012, 46, 1003-1012. [CrossRef]

37. Chorus, C.G. A New Model of Random Regret Minimization. Eur. J. Transp. Infrastruct. Res. 2010, 10, 181-196.

38. Jang, S.; Rasouli, S.; Timmermans, H. Bias in random regret models due to measurement error: Formal and empirical comparison with random utility model. Transportmetrica 2017, 13, 405-434. [CrossRef]

39. Belgiawan, P.F.; Ilahi, A.; Axhausen, K.W. Bali Trans Sarbagita: Comparison between Utility maximization and Regret Minimization. In Proceedings of the 12th International Conference of Eastern Asia Society for Transportation Studies (EASTS) 2017, Ho Chi Minh City, Vietnam, 18-21 September 2017.

40. Charoniti, E.; Rasouli, S.; Timmermans, H.J.P. Context-driven regret-based model of travel behavior under uncertainty: A latent class approach. Transp. Res. Procedia 2017, 24 (Suppl. C), 89-96. [CrossRef]

41. Kim, J.; Rasouli, S.; Timmermans, H. Satisfaction and uncertainty in car-sharing decisions: An integration of hybrid choice and random regret-based models. Transp. Res. Part A 2017, 95, 13-33. [CrossRef]

42. Wang, Z.; An, S.; Wang, J.; Ding, C. Evacuation travel behavior in regret minimization or utility maximization rules? Evidence from emergency context. KSCE J. Civ. Eng. 2017, 21, 440-446. [CrossRef]

43. Jang, S.; Rasouli, S.; Timmermans, H. Incorporating psycho-physical mapping into random regret choice models: Model specifications and empirical performance assessments. Transportation 2017, 44, 999-1019. [CrossRef]

44. Shabanpour, R. Expanding the Applicability of Random Regret Minimization: An exploratory analysis in the context of travel mode choice in the greater Chicago area. Available online: https:/ / utc.uic.edu/wp-content/ uploads/Expanding-the-Applicability-of-Random-Regret-Minimization_Ramin-Shabanpour.pdf (accessed on 21 March 2018).

45. An, S.; Wang, Z.; Cui, J. Integrating Regret Psychology to Travel Mode Choice for a Transit-Oriented Evacuation Strategy. Sustainability 2015, 7, 8116-8131. [CrossRef]

46. Prato, C.G. Expanding the applicability of random regret minimization for route choice analysis. Transportation 2013, 41, 351-375. [CrossRef]

47. Ben-Elia, E.; Ishaq, R.; Shiftan, Y. "If only I had taken the other road...": Regret, risk and reinforced learning in informed route-choice. Transportation 2013, 40, 269-293. [CrossRef]

48. Prato, C.G. Estimating Random Regret Minimization models in the route choice context. In Proceedings of the 13th International Conference on Travel Be haviour Research, Toronto, ON, Canada, 15-20 July 2012.

49. Bierlaire, M. BIOGEME: A free package for the estimation of discrete choice models. In Proceedings of the Swiss Transport Research Conference, Ascona, Switzerland, 19-21 March 2003.

50. Mcfadden, D. Conditional Logit Analysis of Qualitative Choice Behavior. In Frontiers in Econometrics; Academic Press: Cambridge, MA, USA, 1974; pp. 105-142.

51. Temme, D.; Paulssen, M.; Dannewald, T. Incorporating Latent Variables into Discrete Choice Models-A Simultaneous Estimation Approach Using SEM Software. Bur Bus. Res. 2008, 1, 220-237. [CrossRef]

52. D'Souza, C.; Omkar, S.N.; Senthilnath, J. Pickup and delivery problem using metaheuristics techniques. Expert Syst. Appl. 2012, 39, 328-334. [CrossRef]

53. Nam, D.; Kim, H.; Cho, J.; Jayakrishnan, R. A Model Based on Deep Learning for Predicting Travel Mode Choice. In Proceedings of the Transportation Research Board Meeting, Washington, DC, USA, 8-12 January 2017.

(C) 2018 by the authors. Licensee MDPI, Basel, Switzerland. This article is an open access article distributed under the terms and conditions of the Creative Commons Attribution (CC BY) license (http:/ / creativecommons.org/licenses/by/4.0/). 